\title{
An Analysis of Virtual Team Characteristics: A Model for Virtual Project Managers
}

\author{
Sandra Morley', Kathryn Cormican², Paul Folan ${ }^{3}$
}

\begin{abstract}
An integrated model, created to guide project managers, is outlined for the implementation and management of virtual teams. This model is developed by means of an exploratory literature review and an empirical investigation of virtual team utilization in a multinational medical device manufacturer, which examines several factors critical to their success. A TOWS matrix is used to structure the results of the analysis and to identify future virtual team strategies for the organization. The study demonstrates that a structured approach is essential to ensure that the benefits resulting from virtual teamwork are maximized.
\end{abstract}

Keywords: virtual team; collaboration technology; best-practice model; case study; medical devices

\footnotetext{
1,2College of Engineering \& Informatics, National University of Ireland, Galway. Ireland. e-mail: kathryn.cormican@nuigalway.ie (corresponding author).

${ }^{3}$ College of Engineering, Mathematics and Physical Sciences, University of Exeter, Exeter, Devon UK EX4 4SB, UK.
} 


\section{Introduction}

Virtual teams have emerged as a powerful structure in the contemporary business environment, and are characterized by the use of information and communication technologies (ICTs), radical changes in organizational design, and the deployment of a multicultural workforce (Gilson et al, 2014; Greenberg et al., 2007). A virtual team can deliver large strategic, operational or commercial projects involving various concurrent and sequential activities by team members across various geographical localities (LeeKelley and Shanky, 2008). Virtual team formation has also been found useful for enabling organizations to pool the talents of their own employees, and employees of trading partners to meet the demands of today's competitive global environment (Gibson et al, 2014). However, the natural evolution of virtual teams in a dynamic business environment can leave many organizations grappling with a succession of problems, including: the formalization of virtual team work processes and strategies (Carter et al., 20 I5; Lee, 2009); the role of technology in a virtual team environment (Clear and MacDonell, 20I I; Bryant et al., 2009); the issue of virtual team communication (Cramton and Orvis, 2003; Riopelle et al., 2003); the creation of suitable organizational structures for virtual team operations (Bryant et al., 2009; Johnson et al., 200I); and the interaction of personnel that comprise the virtual team and their supporters (Hill et al., 20I4; Fan et al., 20II).

To derive the full benefits of the implemented virtual team structure, it is necessary to contend with these factors, and to create a general framework that may usefully incorporate solutions to the problem areas outlined. Although there is a wealth of research on a range of issues associated with virtual teams and collaboration technologies, no such integrated model is available to guide the managers of large organizations in the implementation and management of virtual teams. This paper fills this research gap by examining the use of virtual teams and collaboration technology, using critical success factors derived from the extant literature. The research is also facilitated by a practical empirical investigation that is carried-out in a multinational medical device company. This allows us to examine virtual teams in an actual company environment, as opposed to a highly structured, though artificial, setting in controlled laboratory settings. Potential strategies for the company regarding the use of virtual teams are explored, and the development of a virtual team model, covering major strands of the current research literature, are proposed and discussed.

\section{Understanding virtual teams}

\section{Defining virtual teams}

The term 'virtual team' is used to cover a wide range of activities and forms of technology-supported working (Shen et al, 20 I 4;Anderson et al., 2007), with the terms 'distributed' or 'dispersed' teams having also been used interchangeably by some researchers (Lee-Kelley, 2006). A review of the relevant literature shows that arriving at an accepted definition of 'virtual teams' has proven contentious. While several definitions state that virtual teams extend across geographical, temporal and organizational boundaries, this viewpoint is not always taken in the literature (Magnusson, et al., 20I4; Munkvold and Zigurs, 2007).Virtual teams, Clear and MacDonell, (20l I) suggest, are work groups whose members are spread over geographic and/or organizational boundaries but are linked together via computer and communication technologies. Huang et al. (2010) posit that virtual teams are technology-enabled, and consist of members who can span different organizations, time zones, geographic locations, and cultures. Virtual project teams, according to Purvanova and Bono (2009), are characterized by temporary lifespan and membership, spatial dispersion, and the use of predominantly computer-mediated communication infrastructures.

In contrast, Johnson et al. (200I), state that the term 'virtual team' can just as easily be applied to groups of people who work no more than 50 feet apart. Distributed work across different locations and/or working times is not a phenomenon of the last 15 years only (Hertel et al., 2005). Kirkman and Mathieu (2005) agree that collocated, faceto-face teams can also exhibit high levels of virtuality. An alternative viewpoint suggests that it is more useful to focus upon the extent to which team members use 'virtual tools' to coordinate and execute team processes-gauging the amount of information value provided by such tools, and the synchronicity of team member virtual interactions-than upon arguments over geographic location, and how far apart team members must be to be considered part of a virtual team (Kirkman and Mathieu, 2005).

There has also been much debate around the definition of the term 'virtual'. Hertel et al. (2005) believe that the extent to which team members are dispersed and their reliance on electronic communication media should be considered dimensions, rather than as dichotomized criteria that distinguish virtual teams from conventional "face-to-face" teams; thus, they believe that it would be better to consider the 'virtuality' of a team. Researchers appear to be moving from defining virtual teams as a type of team that contrasts with a 'traditional' or 'conventional' face-to-face team (e.g. Guzzo and Dickson, 1996), to focusing on 'virtualness' as a potential characteristic of all teams (e.g. Griffith et al., 2003; Munkvold and Zigurs, 2007). 


\section{Benefits of Virtual Teams}

Virtual teaming has been associated with a number of important benefits and advantages over collocated teams. They have been found to facilitate increased participation, as the nature of the communication technology used allows members to contribute based on their own schedules (Shen et al., 20I4).Virtual teams are noted for providing firms with advantages, such as increased utilization of employee-time, round-the-clock workforce availability, and the opportunity to leverage knowledge and expertise around the world (Clear and MacDonell, 20I I).At the individual level, potential advantages of high virtuality include higher flexibility and time control together with higher responsibilities, work motivation, and empowerment of team members (Hertel et al., 2005).

Analyses of virtual team functioning have also found that the number of ideas generated increased with group size, when compared to face-to-face teams (Valacich et al, 1994); while Furst et al. (1999) posit that generating ideas and plans and choosing among alternatives can be completed most effectively through virtual teamwork. The creation of virtual teams also enables team leaders to access a greater pool of employees with the required expertise to address a wider range of problems (Zaccaro and Bader, 2003), and allows organizations to pool talent without having to physically relocate individuals (Greenberg et al., 2007). Virtual team leaders and members have access to a wider range of social contacts than would typically be available in more collocated teams (Zaccaro and Bader, 2003), allowing 'access to a potentially greater base of knowledge' (Griffith et al., 2003).

\section{Critical Success Factors}

Several authors have identified critical factors that attribute to the success of virtual teams. These are collected and grouped into three main areas below: organizational structure, team processes and virtual environment, and people.

\section{Organizational structure}

Requirements for successfully supporting virtual teams, according to Germain and McGuire, (2014) include: human resource policies to recognize, support, and reward virtual team members and leaders; training-both during the initiation of a virtual team and also on a continuous basis; a receptive organizational culture; and continued management support. Rosen et al., (2007) emphasize the requirement to provide teams with the robust, responsive service they need to do their work efficiently. Shen et al., (2014) focus on collaboration and technology readiness, positing previous experience as a critical factor prior to implementation of the virtual team.They highlight the need for the organization to have some experience in collaboration technology before implementing virtual teams. This includes collaboration readiness, and technology readiness.

\section{Team processes and the virtual environment}

Poltrock and Engelbeck (1999) outline the requirements for establishing an environment that can successfully support virtual teaming; including: providing opportunities for interaction that can substitute for those experienced in a traditional team setting; providing visibility for team members on each other's activities, availability and work progress; providing support to different modes of work; and providing an environment that operates as an integrated service, as it supports many people engaged in critical activities. Within this framework of priorities, Rezgui (2007) recommends the inclusion of face-to-face interactions, when possible, during the virtual team lifecycle and in particular during its inception, where the vision, mission, and goals can be communicated and shared. Zigurs (2003) stresses the importance of interspersing face-to-face communication with virtual meetings to help to build relationships and commitment that can enhance team performance. Maznevski and Chudoba (2000) meanwhile recommend that virtual team meetings should follow a 'temporal rhythm' by holding 'regular, intense face-to-face meetings, followed by less intensive, shorter interaction incidents using various media'. Cultural aspects remain important too: while ICTs have been found to mitigate the negative impact of intercultural miscommunication, differences in language, verbal styles, and nonverbal styles were found to influence team effectiveness (Shachaf, 2008).

Rezgui (2007) also offers several recommendations for successful virtual teams: give equal access to information, including project status and progression; develop strong communication and collaboration protocols, including code of conduct, standards for availability and acknowledgement; and establish trust and cohesion among both leaders and team members. Griffith et al. (2003) highlight the need to verbalize rules, terminologies, and descriptions, along with the development of strategies and technologies that support the transfer of knowledge within virtual team settings from individuals, through the group and eventually to organizational-level knowledge. Team empowerment and team-based reward systems are also considered to be crucial (Bryant et al., 2009). Kirkman and Mathieu (2005) highlight team empowerment-defined as an increased task motivation that is due to team members' collective, positive assessments of their organizational tasks (Kirkman and Rosen, 2000)-as an important factor in the performance of virtual teams. Chinowsky and Rojas (2003) believe that teams should be given the power to make independent 
decisions, with teams receiving the greatest independence functioning as better teams, and reducing the likelihood that geographic separation will affect the project outcome.

\section{People}

A consideration of the interaction of personnel that comprise the virtual team and the virtual team's support system is also essential for success. Trust, for example, has been found to be crucial in virtual teams (Schiller et al., 20I4; Germain and McGuire, 20I4), as many tasks are carried out independently and team members must rely on each other's expertise to carry out these tasks successfully. Estimating the level of trust in a virtual team allows the team leader(s) to assess the trustworthiness of each member and the cooperation situation between members (Fan et al., 20l I), while a lack of trust can act as a barrier to knowledge sharing (Rosen et al., 2007).

As members of virtual teams often have different work, discipline, and culture-related cognitive schemata and expectancies of each other's behavior, these tend to act as 'filters' that team members can use when they are operating in a context, trying to achieve a result and perceiving each other's behavior; so that these differences in perception may become a source of misunderstanding and conflict in a virtual team (Rusman et al., 20I0). Instilling all members of a virtual team with a sense of cultural awareness is seen as a vital means of creating trust and openness, particularly in a multi-national organization in which team members may be widely dispersed (Germain and McGuire, 20I4).

Johnson et al.(200I) outline specific qualities required in good virtual team members, including self-discipline, individual accountability, excellent team participation skills, and trust. Rezgui (2007) suggest that it is important to involve project coordinators experienced in virtual team management; and that virtual project managers should exhibit a number of essential attributes that include being: a leader, a 'results catalyst', a facilitator, a 'barrier-buster', a business-analyzer, a coach, and a living example. Minas et al., (2014) suggest that the personality characteristics and psychological profile of virtual team members should also be considered when establishing virtual teams.

\section{Managing virtual teams}

Virtuality has its effect upon the type of management structures put in place to deal with virtual teams, as they begin to be deployed.Virtual team leaders perform a variety of functions within the team, with their role being primarily to develop team members into one cohesive unit, and to constantly monitor and manage ongoing team performance (Bell and Kozlowski, 2002). Reinforcing project objectives, while ensuring that team roles are not in conflict with team members' other commitments, is also identified as key (Chinowsky and Rojas, 2003; Hertel et al., 2005). Furthermore, it is seen as imperative to establish clear conflict resolution procedures in order to avoid minor disagreements between team members, as is the need for virtual team managers to visit dispersed team members to deliver evaluations and to maintain contact (Chinowsky and Rojas, 2003). It is also critically important that managers clearly define the virtual team's role within the context of the organization's greater mission, including the limits of the team's scope and responsibility (Carter et al., 2015).

For Lee (2009), project managers are often required to be both managers and leaders, with managers being responsible for: project initiation; project planning and scope management; time, cost, quality and resource management; and project control. Leaders, on the other hand, are responsible for: project initiating processes; risk management; communication; strategy development and goal setting; and motivating project team members. These tasks, she says, must be balanced. Managers must also overcome individual team member issues, such as feelings of isolation and decreased interpersonal contact, increased chances of misunderstandings and conflict escalation, and increased opportunities of role ambiguity and goal conflicts owing to commitments to different work-units (Hertel et al., 2005). Paul et al. (2004) suggest that a collaborative conflict management style is key to improving the performance of virtual teams, in that they found that a higher level of collaborative conflict management style results in active participation in the group decision making process, and a subsequent perception by virtual team members that the decision-making process is thorough and complete, with a consequent positive reflection on their satisfaction with the overall decision-making process. While a certain level of selfmanagement on the part of the individual team member is practical and necessary when managing at a distance, it is still considered prudent to have regular and structured project status and performance reviews (Lee-Kelley, 2006).

Overall, managers must be politicians (Lee, 2009). While this may seem a negative trait, good political tactics can be positive, ethical, and moral; and can be deployed by project managers to obtain support for projects, promote communication, build the reputation of the project and its deliverables, and influence decision makers in favor of project goals.

\section{Technology in virtual teams}

Technology is a key enabler of the concept under review, and, as such, must be discussed in connection to virtual teams. Given that virtual teams operate differently to face- 
to-face team work, in that team members can be in widely dispersed geographic regions, it follows that technology has a tendency to enable a much wider team discussion than formerly. For Anderson et al. (2007), the supply chain provides a fascinating environment in which to investigate the impacts of technology-supported working, as it highlights the complexities of the contemporary workplace, comprising networks of social and organizational relationships between individuals and companies. Advances in technology facilitate communication, and the sharing of information among team members; as well as giving organizations access to a larger pool of skills (Shen et al., 20l4; Greenberg et al., 2007), which can reduce product development time, increase organizational performance, lateral communication, and employee participation (Clear and MacDonnell, 20I I). Lists of technologies actually recommended for virtual team work range from the sophisticated to the standard, and from communication mechanisms that are both synchronous and asynchronous in operation. Their usefulness for supporting virtual teams is generally assessed by means of empirical observation of study groups deploying the technologies in a virtual setting.

While Shachaf (2008) has noted that ICTs may go beyond their intended remit of simply overcoming geographical and time zone differences, to providing support for the creation and maintenance of team identity; they may also present a number of new contextual problems not familiar from face-to-face communication. Lee (2009) asks whether, in the emerging world of ethical monitoring of electronic systems, this may not lead to a multitude of ethical questions regarding privacy, trust, and employee rights, with virtual team managers needing to understand the ramifications of monitoring programs on the dynamics of virtual project work. There is the additional expense of training on the technologies to be used (Greenberg et al., 2007), and the alignment of technology used across multiple time zones, when the logistics of virtual team meetings are likely to become extremely complex (Shachaf, 2008).

\section{Research methodology}

The aim of the study was to gather concrete, practical and context-dependent knowledge about virtual teams in a specific environment. Consequently a comprehensive inductive case study was used to collect the data required. According to Yin (2014) case studies allow for a detailed contextual analysis of a limited number of events or conditions and their relationship. They are lauded to be a valuable way of examining complex real-life situations. They are also used to explain a situation and to provide a basis to apply solutions to situations (Huberman and Miles, 2002). In this approach questions, insights, propositions, and pictures emerge from the data collection process. According to
(Rowley 2002) case study research employs analytical rather than statistical generalization techniques. Here 'previously developed theory is used as a template with which to compare the empirical results of the case study'.

The unit of analysis in this study in this study comprised employees in the Irish site of a large multinational medical device organization who worked in a virtual team. These spanned many functions including product design, manufacturing, supply chain management and senior management. The goal of the study was to review the systems and technologies provided at an organizational level to facilitate collaboration; examine the teams currently working virtually in the company, separated by either location or time; and determine the success of virtual teaming in the company by canvassing opinions from virtual team members. Utilizing a semi-structured interview format, respondents from selected virtual teams were asked a set of applicable questions, which included information about the frequency of virtual team participation versus faceto-face meeting, technologies deployed, training received, perceived advantages and disadvantages of virtual team work, and management perceptions of the technologies and guidance required to support distributed teamwork. A non-probabilistic sampling method was favored to target respondents as statistical generalization was not one of our research objectives (Merriam, 20I4). Purposeful sampling, or selecting a sample from which the maximum can be learned, was deemed be most appropriate for this study. Interviews continued until saturation point i.e. where no new data emerged. Where necessary additional documentation was supplied and explained to clarify any outstanding issues that respondents may have had in answering the questions.

Great care and attention was paid to maintaining scientific rigor in our study. Data collection techniques followed best practice in order to ensure reliability and validity. Interview questions were derived from the literature to steer the interviews. A pre-test combined with 3 pilot tests were conducted in advance to ensure that the correct information was gathered and that there was no ambiguity in the questions posed. Interviews lasted between 45 and 70 minutes. The answers to the questions were recorded by hand. Structured templates were used to ensure that the information was recorded in the same way for each interview. Case notes were written up within 24 hours of the interview. Clarifications and amendments were made where necessary. In order to satisfy Yin's (2009) requirement of linking the data to the proposition the analysis of the findings was based on the theoretical propositions. Furthermore a chain of evidence was maintained.

A TOWS matrix is used to structure the findings (Weihrich 1982). This study presents a three-step adaptation of the 
TOWS methodology: first, an analysis of the enterprise and its current approach to virtual teaming is given, which includes a survey of virtual team members to understand their experiences; secondly, these results are subsequently adapted to the TOWS matrix structure, and from this, potential strategies are identified and evaluated; and thirdly, using the information gathered in the case study,alongside that from the literature review, a model for the implementation and management of virtual teams is presented and assessed.

\section{Virtual Teams in Practice:A Case Study of a Multinational Medical Device Manufacturer}

\section{Enterprise Profile}

MedicDev is a world-wide developer, manufacturer and marketer of medical devices with approximately 25,000 employees worldwide. It has several facilities throughout the US, along with sites in Belgium, Costa Rica, Ireland, Japan, Netherlands, and Puerto Rico. MedicDev use a number a corporate-wide systems including HR Connect, and Learning Connect for locating, completing, and tracking training at MedicDev. PDM (Product Data Management), an electronic change control system, enables users to manage all product documentation facilitating the ability to design anywhere/build anywhere. It also uses GLS (Global Labeling System) for product labeling, and SAP (Systems, Applications and Products) incorporating functions such as customer service, distribution, planning, manufacturing and finance. MedicDev acquired a major medical device manufacturer in 2006 and another in 2014. Thus, one of the key drivers of improvements in communications technologies within MedicDev as a whole is the need to integrate former employees of the acquired firms into the MedicDev organization. This has led to improvements in MedicDev's Information Systems (IS) infrastructure. In this paper we focus upon the Irish branch of MedicDev, and examine the linkages across Irish and international operations accordingly. Analysis of the virtual teams was carried out to understand how successful and effective this work structure is in MedicDev. Table I gives a brief outline of virtual team work carried out by MedicDev's functions and departments, and summarizes how participants are physically separated (by geography, by time, or by function).

\begin{tabular}{|c|c|c|c|c|}
\hline $\begin{array}{l}\text { Example of virtual } \\
\text { teamwork }\end{array}$ & Description & 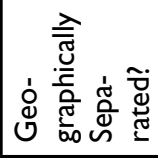 & 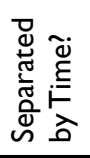 & 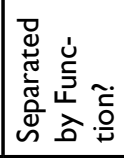 \\
\hline $\begin{array}{l}\text { Corporate Risk Assess- } \\
\text { ment Function }\end{array}$ & $\begin{array}{l}\text { Functional group. Director is based in Ireland, with } \\
\text { members from two other sites }\end{array}$ & Yes & Yes & No \\
\hline $\begin{array}{l}\text { Field Action Reporting } \\
\text { System (FARS) Business } \\
\text { Process Lead (BPL) }\end{array}$ & $\begin{array}{l}\text { FARS administrator for all Irish sites, who works as } \\
\text { part of teams investigating potential product issues } \\
\text { in the field. May be a member of several investiga- } \\
\text { tion teams simultaneously. }\end{array}$ & Yes & No & Yes \\
\hline Operations Training & $\begin{array}{l}\text { Functional group, supporting a } 24 \text { hour } / 6 \text { day a } \\
\text { week shift pattern (with members working } 3 \times 12 \\
\text { hour shifts), with a supervisor working a five day } \\
\text { week on day shift. }\end{array}$ & No & Yes & No \\
\hline $\begin{array}{l}\text { Project Teams (Prod- } \\
\text { uct-related) }\end{array}$ & $\begin{array}{l}\text { Multi-functional groups, with members from other } \\
\text { sites, working towards a specific goal (e.g. product } \\
\text { launch). }\end{array}$ & Yes & Yes & Yes \\
\hline $\begin{array}{l}\text { Project Teams (Sys- } \\
\text { tem-related) }\end{array}$ & $\begin{array}{l}\text { Cross-site (Ireland and US) team focused on risk } \\
\text { management process.Various multi-site teams } \\
\text { working on quality system-related projects. }\end{array}$ & Yes & Yes & No \\
\hline $\begin{array}{l}\text { Dual-site Documen- } \\
\text { tation \& Packaging } \\
\text { Graphics Departments }\end{array}$ & $\begin{array}{l}\text { Departments based in two different sites (Ireland } \\
\text { and US) who report to one manager/director. }\end{array}$ & Yes & Yes & No \\
\hline
\end{tabular}

Table I.Virtual teamwork in MedicDev

ISSN: 07I 8-2724. (http://www.jotmi.org)

Journal of Technology Management \& Innovation (c) Universidad Alberto Hurtado, Facultad de Economía y Negocios. 
A list of advantages and disadvantages associated with working in a virtual team, as reported by the study's respondents, is given in Table 2 .

\section{Analysis of Virtual Teaming in MedicDev}

A TOWS matrix (Weihrich 1982), has been used to analyze the state of virtual teaming in MedicDev (see table 3) and to determine what strategies the organization should follow to maximize the use of collaboration technologies. The matrix pairs the factors identified during a SWOT analysis to suggest new strategies for the organization. There are four types of resultant strategy, usually arranged in a gridlike structure namely
- The SO (Strength-Opportunity) Strategy, which aims to maximize both the strengths and opportunities of the organization.

- $\quad$ The ST (Strength-Threat) Strategy, which aims to maximize the strengths and minimize the threats.

- $\quad$ The WO (Weakness-Opportunity) Strategy, which aims to minimize the weaknesses and to take advantage of the opportunities identified. This is a developmental strategy, which means the company takes steps to transform weaknesses into strengths (Weihrich, 1993).

- $\quad$ The WT (Weakness-Threat) Strategy is aimed at minimizing both the weaknesses and threats.

Based on the results, potential future strategies for the company regarding the use of virtual teams are explored. A best-practice model, of practical interest to management, which allows for the implementation of successful virtual teaming in multinational organizations, is also proposed, based upon experiences from the case study.

\begin{tabular}{|l|l|}
\hline Advantages of Virtual Teamwork & Disadvantages of Virtual Teamwork \\
\hline Time differences allow more time for team members & Lack of personal contact - "out of sight, out of \\
to provide feedback & mind" - can lead to feelings of isolation \\
Distributed team members provide different perspec- & Some information is more easily shared face-to-face \\
tives on issues & Can take longer to get work done - more expla- \\
More flexibility & nation required, more meetings required to gain \\
Reduced office space required & consensus \\
Larger pool of knowledge & Greater opportunities for misinterpretations and \\
Less travel required & conflict \\
Team size is not a concern & Difficulties in reaching consensus due to disparity in \\
Technology makes it easier to keep in contact & culture/systems/processes \\
E-mail can be kept as records & Day-to-day activities may cause distractions from \\
Time to formulate responses & team tasks \\
Increased pool of contacts & Often insufficient face-to-face time to promote \\
Fewer face-to-face meetings required & team building and to build personal relationships \\
Able to play role in corporate teams & Differences in time zones or work patterns make \\
Easier to get experienced people involved & it difficult to implement changes and schedule \\
Can learn from people in other sites & meetings \\
Easier to maintain relationships with colleagues in other & Lack of meeting etiquette/guidelines can make com- \\
locations & munications frustrating \\
& Less respect/understanding of status and experience \\
of other team members \\
Less camaraderie among team members
\end{tabular}

Table 2: Perceived Advantages/Disadvantages of Virtual Teaming in MedicDev

ISSN: 07 I 8-2724. (http://www.jotmi.org) 


\begin{tabular}{|c|c|c|}
\hline & Internal Strengths & Internal Weaknesses \\
\hline & $\begin{array}{l}\text { Highly skilled workforce } \\
\text { Recognition and reward of successful } \\
\text { workers } \\
\text { Robust infrastructure } \\
\text { Centralized HR function } \\
\text { People with experience of } \\
\text { virtual work at all levels of the organiza- } \\
\text { tion } \\
\text { Several collaboration technologies in } \\
\text { use } \\
\text { Collaboration is part of the organiza- } \\
\text { tions culture }\end{array}$ & $\begin{array}{l}\text { Little training on technologies } \\
\text { No formal training on managing virtual } \\
\text { teams } \\
\text { No training on how to work in a virtual } \\
\text { team } \\
\text { No formal guidelines on choosing the } \\
\text { most suitable technologies } \\
\text { Lack of awareness of the importance } \\
\text { and value of virtual teaming and associ- } \\
\text { ated processes/technologies }\end{array}$ \\
\hline External Opportunities & Strength | Opportunity (SO) & Weakness | Opportunity (WO) \\
\hline $\begin{array}{l}\text { Wide range of applicable technologies } \\
\text { available } \\
\text { Cost reduction through increased use } \\
\text { of technology and reduction in travel or } \\
\text { relocation expenses } \\
\text { Increased use of collaboration tech- } \\
\text { nologies would mean less time spent } \\
\text { travelling }\end{array}$ & $\begin{array}{l}\text { Encourage increased use of collabora- } \\
\text { tion technologies to form virtual teams } \\
\text { in MedicDev } \\
\text { Investigate the technologies currently } \\
\text { available and provide criteria for assess- } \\
\text { ing and choosing the right system }\end{array}$ & $\begin{array}{l}\text { Develop a set of tools | best practices } \\
\text { for the management of virtual teams } \\
\text { Provide training on the use of collabo- } \\
\text { ration technologies } \\
\text { Provide training or guidance on working } \\
\text { in a virtual team } \\
\text { Provide tools for project managers } \\
\text { to source and identify the right team } \\
\text { members, regardless of location within } \\
\text { the organization }\end{array}$ \\
\hline External Threats & Strength | Threat (ST) & Weakness | Threat (WT) \\
\hline $\begin{array}{l}\text { Not optimizing resources by failing to } \\
\text { maximize the } \\
\text { advantages presented by use of collabo- } \\
\text { ration technologies } \\
\text { High fuel costs internationally, resulting } \\
\text { in elevated travel costs }\end{array}$ & $\begin{array}{l}\text { Encourage increased use of collabora- } \\
\text { tion technologies in MedicDev to offset } \\
\text { travel costs }\end{array}$ & $\begin{array}{l}\text { Permanently relocate personnel to } \\
\text { primary project location }\end{array}$ \\
\hline
\end{tabular}

Table 3.TOWS Matrix for MedicDev's Performance with Virtual Teaming

ISSN: 07 I8-2724. (http://www.jotmi.org) 


\section{Proposed future strategy for MedicDev}

The proposed strategies identified after our analysis must be carefully evaluated before a choice is made. An evaluation of the risks involved, the timing associated with the introduction of a new strategy, and the reaction of key stakeholders must be considered.

SO Strategy I: Encourage and facilitate increased use of virtual teaming.An increased use of collaboration technology to facilitate work practices and teamwork has been noted across all organizations. Therefore, the continued use of these technologies is a logical strategy to pursue. However, a more formal, structured approach is required to ensure that teams using technology to communicate and share information perform as effectively as possible.

SO Strategy 2: Investigate the technologies currently available and provide guidelines for choosing the right system from those currently available. This strategy is an extension of the first proposed strategy. A critical part of introducing a structured and integrated approach to virtual teaming is the provision of knowledge and tools to allow team managers to identify the most appropriate tools for the task at hand.

WO Strategy: Develop a structure to adequately support virtual teams, including guidance on best-practices, appropriate technologies, and training. This strategy focuses on the weaknesses identified during the analysis of virtual teams currently working within MedicDev. The opportunities show that the organization is ready for increased usage of virtual teams. However, to do this successfully, huge improvements are needed in the ways that virtual teamwork is currently viewed and supported within the organization.

ST Strategy: Reduce travel costs by encouraging and facilitating virtual teaming. This strategy provides a solution to the increased costing of business travel by encouraging and facilitating increased usage of the virtual team structure and associated technologies.

WT Strategy: Permanently relocate personnel to primary project location. This strategy may be viable where key team members are required to devote $100 \%$ of their time to a critical project. However, as a corporate-wide policy, it is not feasible.

The organization should pursue a strategy of formalizing the use of virtual teams, which requires changes at an organizational level.This includes providing adequate guidance and training on creating and managing virtual teams, and on choosing and implementing the most appropriate tools for these teams. Therefore, four of the five strategies identified can be pursued concurrently, as they are inter-related. The analysis of the current status of virtual teaming in MedicDev has shown a level of frustration around virtual teamwork, which indicates that there would be significant support for initiatives to improve its performance. Continuing developments in technology, along with improvements in infrastructure, mean that virtual teams' processes are continuously being improved. Therefore, the timing of the implementation of these strategies is ideal.

\section{A model for the implementation and management of successful virtual teams}

Based on the analysis discussed earlier, it is clear that a multinational organization such as MedicDev must pursue a strategy that supports the creation and management of virtual teams in a systematic manner. The most important issues identified during the analysis relate to: the lack of training available for virtual teams; the lack of appropriate tools and technology; of a properly structured approach to virtual team formation; and the absence of a general, coherent understanding of what virtual teams provide to an organization. Other, additional, factors highlighted by the case study relate to the greater difficulty of sharing information virtually, as opposed to face-to-face and of reaching consensus due to disparity in culture/systems/processes. The lack of personal interaction involved in virtual teams was also found to increase incidences of misinterpretation and lead to feelings of isolation and general dissatisfaction among virtual team members. The model proposed here aims to address these issues within a coherent, structured framework for the successful implementation and support of virtual teams.

The model identifies four key areas that must be addressed to facilitate successful technology-enabled collaboration between work teams. These areas are: (a) essential conditions for success; (b) organizational level tasks; (c) introduction of new technologies; and (d) creation and management of virtual teams. The model is conceptualized in Table 4. 


\begin{tabular}{|c|c|c|c|}
\hline $\begin{array}{l}\text { Essential Conditions for } \\
\text { Success }\end{array}$ & $\begin{array}{l}\text { Organizational Level } \\
\text { Tasks }\end{array}$ & $\begin{array}{l}\text { Introduction of New } \\
\text { Technologies }\end{array}$ & $\begin{array}{l}\text { Creation and Manage- } \\
\text { ment of Virtual Teams }\end{array}$ \\
\hline $\begin{array}{l}\begin{array}{l}\text { Support of senior man- } \\
\text { agement }\end{array} \\
\text { Robust IT Infrastruc- } \\
\text { ture } \\
\text { Technologically Ad- } \\
\text { vanced Corporate } \\
\text { Culture }\end{array}$ & $\begin{array}{l}\text { Establish ownership for } \\
\text { virtual team support } \\
\text { Identify collaboration } \\
\text { tools already in use } \\
\text { Identify virtual teams } \\
\text { that currently operate } \\
\text { successfully } \\
\text { Develop toolkit for } \\
\text { virtual teams } \\
\text { Develop training mate- } \\
\text { rials on tools } \\
\text { Develop Guidelines for } \\
\text { Identifying and Intro- } \\
\text { ducing new technolo- } \\
\text { gies }\end{array}$ & $\begin{array}{l}\text { Detailed mapping to } \\
\text { ensure technology fits } \\
\text { Design of new technolo- } \\
\text { gy should involve future } \\
\text { users } \\
\text { Where possible new } \\
\text { technologies should be } \\
\text { aligned with existing } \\
\text { ones } \\
\text { Local champions should } \\
\text { be identified } \\
\text { Rewards/benefits of new } \\
\text { technologies should be } \\
\text { emphasized } \\
\text { Adequate support } \\
\text { should be provided for } \\
\text { new technologies } \\
\text { Clear guidelines and } \\
\text { training to be provided }\end{array}$ & $\begin{array}{l}\text { Team manager must be } \\
\text { trained on specific skills } \\
\text { required to manage VTs } \\
\text { Chose team members } \\
\text { with appropriate skills } \\
\text { Provide training on } \\
\text { working in virtual teams } \\
\text { including technologies } \\
\text { Teams reporting } \\
\text { structure to be clearly } \\
\text { defined } \\
\text { Provide opportunities } \\
\text { for interaction and trust } \\
\text { development } \\
\text { Establish rules of en- } \\
\text { gagement } \\
\text { Establish clear goals and } \\
\text { responsibilities } \\
\text { Ensure team are aware } \\
\text { of how their work sup- } \\
\text { ports the overall goals } \\
\text { of the organization } \\
\text { Manager to visit remote } \\
\text { as possible }\end{array}$ \\
\hline
\end{tabular}

Table 4. Model for the Implementation of Virtual Teams and Associated Technologies 


\section{Essential conditions for success}

An organization must have several fundamental characteristics in order successfully to support the implementation of virtual teaming and associated technologies. Firstly, the support of senior management is essential: not only are they required to advocate the use of virtual teaming; but they must drive the necessary corporate-wide changes to systems and policies that are required, and ensure that resources needed are made available. The organization's IT infrastructure must also be fully up-to-date and common to all team members, in order to ensure that new technologies and increased network traffic can be accommodated, and that geographically-dispersed team members can have equal input and access to information and opportunities. Lastly, the organization must be open and receptive to change, and preferably have a culture or history of knowledge-sharing, or at least a high degree of familiarity and ease with the use of technologies and systems.

\section{Organizational level tasks}

If the pre-requisites cited above are met, the organization must turn its attention to establishing policies and processes to support the establishment and management of virtual teams. It is essential that a responsible group is identified at an organizational level to provide focus for maintenance activities, to manage feedback, and to support virtual teams at other sites within the organization. Large organizations should have a centralized owner of the virtual team initiative to ensure that a common approach is maintained throughout, and that a common language is used when working with virtual teams. At the outset of a formal virtual teaming initiative, it is important to identify the existing teams within the organization who are already successfully using collaboration technologies, as their methodologies and the collaboration tools they use could underpin a bestpractice model for the organization and provide a 'tool-kit' for new teams. It is also vital that corporate-wide training material be developed to ensure that the tools identified are fully utilized in a common way, ensuring that all team members can be fully involved, regardless of language or geographical location. Guidelines should be established at the corporate level to ensure that any risks associated with the introduction of new technologies are assessed consistently, and that lessons learned at one site can be shared appropriately. HR policies relating to the selection of suitable virtual team managers and members should also be established, and training must be provided, which increases awareness of the suitable behaviors associated with communication technology rather than face-to-face encounters, and which establishes criteria for identifying and rewarding successful teams.

\section{Introduction of new technologies}

A properly structured approach is particularly critical in relation to the introduction of new technologies. Before a new collaboration technology is implemented, there must be a detailed mapping of the existing tools used within the organization of the experience of intended users, along with the capability of the IT infrastructure, in order to ensure that the proposed technology 'fits' the requirements of the team and the organization. Before this mapping can take place, it is vital that there is a clear understanding of the tasks to be performed by the technology. When a new technology or system needs to be designed (or customized to meet the needs of the organization), it is critical that input is sought from the future users of the new system as well as current users, and that the support of key stakeholders, such as the organization's leadership, is established early in the project.

System experts and champions should be identified to facilitate acceptance and awareness of the rewards and benefits associated with the new technology. Any new technologies should be aligned to work in conjunction with existing technologies, systems, and business processes to maximize their usefulness and effectiveness. Ongoing technical support should be made available for new technologies, and its performance should be monitored before and after implementation to establish criteria to evaluate its success. Finally, formal training material should be developed for all new technologies, in addition to manuals and procedures governing the use of the system, and its implementation should be timed carefully to meet the needs of the organization. 


\section{Creation and management of virtual teams}

The team manager must have the appropriate characteristics and skills required to manage the virtual team. These include: the ability effectively to manage communication; to develop relationships with team members, recognizing their opinions and suggestions; and to identify and address issues of low motivation and conflict within the team. They should also encourage self-leadership and be able to recognize emergent leaders, promote and maintain team trust and cohesion, and studiously monitor team performance. It is also crucial that they ensure that appropriate tools are available for all aspects of the work to be performed by the virtual team, and that they lead by example as far as the adherence to team processes and the use of collaboration tools are concerned. It is important that the team members selected have the appropriate skills for working on a virtual team. These include:

- Self-management and self-discipline, with individual accountability;

- Openness to technology and technological change;

- Excellent team-participation skills, with experience

of working in teams, particularly in using technology to communicate;

- $\quad$ Propensity to trust-i.e. to have confidence in other team members to fulfill their tasks and to behave in a consistent and predictable manner; and

- Suitable personality traits that include: patience, perseverance, persistence, tolerance, flexibility, and understanding.

It is also critical that team participants should be trained on how to work effectively in a virtual team, and that team members, regardless of location, should receive the same level of training. This should include guidelines on using communications tools such as email, voicemail and audioand video-conferencing effectively, and cultural awareness for multinational teams. Furthermore, team members must understand where they fit within the team itself, and also where the team lies within the overall organization. It is recommended that virtual teams should meet face-to-face at least at the initial formation of the team, to help in the creation of relationships and trust between members. Teams should be given opportunities to interact outside of formal group meetings; more informal, social interaction has been shown to lead to more productive teams as it helps to establish trust and to create a shared group identity.
Finally, clear rules of engagement should be established during the team's formation. These should include:

- The establishment of equal access to information for all members;

- Promotion of continuous communication between team members;

- Continuous performance feedback from the team manager;

- The establishment of norms around the use of communication technologies, including terminologies to support knowledge transfer; and

- The establishment of a clear code of conduct, along with standards for availability and acknowledgement, plus the establishment of guidelines for meetings and discussions to ensure that minor disagreements do not escalate.

To work effectively, clear goals and responsibilities should be established.Adherence to these should be monitored by the team manager. It is important that the team roles assigned do not conflict with team members' commitments to other work units. The importance of the work carried out by the team in relation to the overall organization should be emphasized. Where team members are in geographicallydispersed locations, it is important for the team manager to visit remote team members to counteract any feelings of isolation that may arise.

Comparison of virtual team model against current literature For organizational level issues, commentators such as Carter et al, (2015) and Germain and McGuire, (2014) and have highlighted the requirements for human resource policies to recognize, support, and reward virtual team members and leaders, the provision of training, a receptive organizational culture, continued management support, the provision of adequate support organizations, and experience in collaboration technology. These issues are collectively tackled in the 'organizational level' and 'conditions for success' portions of the model, where issues such as ownership, senior management support, collaboration technologies, and training are addressed.

Similarly, the 'creation/management level' provides detailed support for what may be termed 'team processes' and 'virtual environmental' factors. Zakaria and Yusof, (2015) outline the need for favorable interaction opportunities in virtual teaming, virtual team visibility, support for different work modes (including the mixing of face-to-face and virtual team meetings (Maznevski and Chudoba, 2000; Zigurs, 2003; Rezgui, 2007), and the provision of an integrated service environment for the operation of the virtual team, including the avoidance of 'intercultural miscommunication' (Shachaf, 2008). Team empowerment and team-based reward systems (Kirkman et al., 2004; Bryant et al., 2009) are also

ISSN: 07 I8-2724. (http://www.jotmi.org)

Journal of Technology Management \& Innovation @ Universidad Alberto Hurtado, Facultad de Economía y Negocios. 
considered in the model, in the provisions made for each aspect of the team process and the actual operative virtual environment itself.

People are examined too, as it is acknowledged that a consideration of the interaction of personnel that comprise the virtual team and the virtual team's support system is of considerable importance if the virtual team is to be a success. The model widely supports the tenets proposed by Johnson et al. (200I) on this subject: self-discipline of virtual team members, individual accountability for results, a focus on team participation skills, and issues of trust. In particular, virtual team trust (Schiller et al., 20 I4; Germain and McGuire, 20I4; Fan et al., 20I I) is tackled in the "creation/management level' of the model, as too is the issue of instilling all members of a virtual team with a sense of cultural awareness (Zakaria and Yusof, 2015). Managing virtual teams is also not neglected (Lee-Kelley, 2006; Greenberg et al., 2007; Lee, 2009): tools for tackling personality characteristics and psychological profiling of team members, building teams with appropriate skills, and management's role in team creation are addressed in the 'organizational level' segment, and the 'creation/ management level' segment of the virtual team model.

Finally, the critical success factors surrounding the introduction of new technologies (Shen et al., 2014; Clear and MacDonell, 20II; Shachaf, 2008; Bryant et al., 2009), such as: mapping technologies against existing organizational infrastructure to ensure an adequate fit, designing and implementing new technologies, aligning new technologies with existing technologies in the firm, providing incentives for the adoption of new technologies, technology support, and guidelines for usage: these are addressed in the 'technology section' of the virtual team model.

\section{Conclusions}

Developments in information and communication technologies, along with a drive towards flatter, leaner organizations, have contributed to the growth of virtual teams. Although there is a wealth of research on a range of issues associated with virtual teams and collaboration technologies, no integrated model is available to guide project managers of large organizations in the implementation and management of virtual teams. The purpose of this paper was to develop a model for the implementation and management of virtual teams using the information gathered from reviews of literature concerning virtual teams and collaboration technologies, along with an analysis of the virtual team experience in a modern multinational organization.

To investigate how virtual teams and collaboration technologies are implemented and managed in an organizational setting, a case study of a multinational medical device manufacturer has been carried out. This study involves an analysis of the current approach to virtual teaming in this organization, including a survey of virtual team members to understand their experiences, and a review of the technologies available to facilitate collaboration. A TOWS matrix is used to structure these findings. From this, potential strategies are identified and evaluated. Finally, using the information gathered in the case study, along with the literature reviews, a model for the implementation and management of virtual teams is presented and assessed.

Provided that the organization is prepared to invest in the necessary updating and maintenance of the relevant IT infrastructure, and in providing systematic training and recruitment, there are a number of key benefits associated with the implementation of the resultant virtual team model. It provides a holistic framework that takes into account the specific skills and abilities that are most appropriate for working in a dispersed team, as well as meeting requirements at the overall organizational level. Furthermore, it emphasizes the importance of the organization's culture and attitude towards change and incorporating new systems and processes, and the need for senior management support to ensure that tools and techniques are disseminated appropriately throughout the business.

Limitations of the virtual team model proposed should also be noted; these include:

- The model has been developed principally from one in-depth case study of a multinational medical device manufacturer, and would benefit from additional studies carried-out in other industries, and from the opinions and experience of managers practice virtual team creation and implementation;

- Full implementation of the model would mean a considerable investment of time and money to ensure that the organization could meet the requirements of the model-this investment, it is acknowledged, may be difficult to secure;

- It may be difficult to garner adequate support at all levels of the organization to ensure that the guidelines outlined in the model are disseminated and integratedthis may be a particular problem in large organizations with employees from many different countries and cultures;

- It is imperative to assign an owner to the model. For the model to work in a dispersed organization, an owner for the support of virtual teaming would have to be identified;

- $\quad$ Choosing team members with the skills outlined in the model may not be possible if teams are already in place, and managers do not always have the opportunity to choose new members. 
The literature reviewed relating to virtual teams was mainly concerned with teams formed to complete a particular object or task. From the case study, it is evident that other, more permanent forms, of virtual teams exist. In MedicDev, some departments and functional groups have been reorganized permanently to incorporate members from more than one site. In addition, production demands mean that some teams are permanently separated by shift patterns. Little or no research has been carried out on the specific challenges faced by such teams, but owing to the increased global nature of business-and the benefits presented by further developments in collaboration technologiesthis scenario will become more common, particularly in multinational organizations.

The virtual team model presented in this study incorporates the guidelines for successful virtual teams and technology implementation. However, its true value can only be established through its application in organizations. This study demonstrated that MedicDev does not have a structured approach to virtual teaming. This can be explained to some extent by the emergent nature of this form of teamwork and the rapid growth in technologies that can facilitate collaboration in dispersed work groups. As a result, the absence of an appropriate structure for virtual teamwork would be expected in many organizations. Further research is required to determine if this is, in fact, the case.

\section{References}

ANDERSON, A.H., McEwan, R., Bal, J., Carletta, J. (2007). Virtual team meetings: An analysis of communication and context. Computers in Human Behavior, 23, 2558-2580. doi:I0.1016/j.chb.2007.0I.00I

BELL, B.S., Kozlowski, S.W.J. (2002). A typology of virtual teams: Implications for effective leadership. Group \& Organization Management, 27(I), 14-49. doi: I0.1177/1059601102027001003

BRYANT, S.M., Albring, S.M., Murthy, U. (2009). The effects of reward structure, media richness and gender on virtual teams. International Journal of Accounting Information Systems, I0, I90-2 13. doi:10.1016/j.accinf.2009.09.002

CARTER, D.R., Seely, P.W., Dagosta, J., DeChurch, L.A., Zaccaro, S.J. (2015). Leadership for global virtual teams: Facilitating teamwork processes. In Wildman, J.L, Griffith, R.L. (Eds) (2015) Leading Global Teams (pp. 225-252). Springer, New York. doi:I0.1007/978-I-4939-2050-I_10

CHINOWSKY, P.S., Rojas, E.M. (2003). Virtual teams: guide to successful implementation. Journal of Management in Engineering, 19(3), 98-106. doi:10.1061/(ASCE)0742$597 \times(2003) 19: 3(98)$

CLEAR,T., MacDonell, S.G. (20I I). Understanding technology use in global virtual teams: Research methodologies and methods. Information and Software Technology, 53(9), 994I0II. doi:10.1016/j.infsof.201I.01.01 I

CRAMTON, C.D., Orvis, K.L. (2003). Overcoming barriers to information sharing in virtual teams. In: Gibson, C.B., Cohen, S.G. (Eds.), Virtual Teams that work: Creating conditions for virtual team effectiveness, Jossey-Bass, San Francisco.

FAN, Z.P., Suo, W.L., Feng, B., Liu,Y. (20I I).Trust estimation in a virtual team: $A$ decision support method. Expert Systems with Applications, 38(8), 10240-1025I. doi:10.1016/j. eswa.20II.02.060

FURST, S.A., Blackburn, R.S., Rosen, B. (1999). Virtual team effectiveness: A proposed research agenda. Information Systems Journal, 9(4), 249-269. doi: 10.1046/j.13652575.1999.00064.x

GERMAIN, M L., McGuire, D. (2014). The role of swift trust in virtual teams and implications for human resource development. Advances in Developing Human Resources, 16(3), 356-370. doi: I0.1 I77/I5234223 | 4532097

ISSN: 07 I8-2724. (http://www.jotmi.org) 
GIBSON, C.B., Huang, L., Kirkman, B.L., Shapiro, D.L. (20I4). Where global and virtual meet: The value of examining the intersection of these elements in twenty-first-century teams. Annual Review of Organizational Psychology and Organizational Behavior, I ( I), 2 17-244. doi: 10.1 I 46/annurevorgpsych-03|4|3-09|240

GILSON, L.L., Maynard, M.T., Young, N.C.J., Vartiainen, M., Hakonen, M. (2014). Virtual Teams Research 10 Years, 10 Themes, and 10 Opportunities. Journal of Management, doi: |0.1 177/0|49206314559946

GREENBERG, P.S., Greenberg, R.H., Antonucci, Y.L. (2007). Creating and sustaining trust in virtual teams, Business Horizons, 50(4), 325-333. doi:10.1016/j.bushor.2007.02.005

GRIFFITH, T.L., Sawyer, J., Neale, M. (2003). Virtualness and knowledge in teams: managing the love triangle of organizations, individuals, and information technology, MIS Quarterly, 27(2), 265-87.

GUZZO, R.A., Dickson, M.W. (1996). Teams in organizations: Recent research on performance and effectiveness. Annual review of psychology, 47(I), 307-338. doi: 10.1 I46/annurev. psych.47.I.307

HERTEL, G., Geister, S., Konradt, U. (2005). Managing virtual teams: A review of current empirical research. Human Resource Management Review, I5(I), 69-95. doi:10.1016/j. hrmr.2005.01.002

HILL, N.S., Lorinkova, N., Karaca, A. (2014). A critical review and meta-analysis of leadership behaviors and virtual teams performance.Academy of Management Proceedings, 20 I4, I, 12990-I2990. doi: 10.5465/AMBPP.20 I 4. I2990abstract

HUANG, R., Kahai, S., Jestice, R. (2010). The contingent effects of leadership on team collaboration in virtual teams. Computers in Human Behavior, 26(5), 1098-1II0. doi:10.1016/j.chb.2010.03.014

HUBERMAN, M., Miles, M.B. (Eds.). (2002). The qualitative researcher's companion. Sage. doi: I0.4|35/978|4|2986274

JOHNSON, P., Heimann, V., O'Neill, K. (200I). The "wonderland" of virtual teams. Journal of Workplace Learning, I3(I), 24-29. doi: I0.1 I08/I3665620I I 0364745

KIRKMAN, B.L., Mathieu, J.E., (2005). The dimensions and antecedents of team virtuality, Journal of Management, 3 I (5), 700-7|8. doi: 10.1 |77/0| 49206305279|I3
LEE, M.R., (2009). E-ethical leadership for virtual project teams, International Journal of Project Management, 27(5), 456-463. doi:10.1016/j.ijproman.2008.05.012

LEE-KELLEY, L. (2006). Locus of control and attitudes to working in virtual teams. International Journal of Project Management, 24(3), 234-243. doi:10.1016/j. ijproman.2006.01.003

LEE-KELLEY, L., Sankey, T. (2008). Global virtual teams for value creation and project success:A case study, International Journal of Project Management, 26(I), 5I-62. doi:10.1016/j. ijproman.2007.08.010

MAGNUSSON, P., Schuster, A., Taras, V. (2014). A processbased explanation of the psychic distance paradox: evidence from global virtual teams. Management International Review, 54(3), 283-306. doi: $\mid 0.1007 /$ s | |575-0|4-0208-5

MAZNEVSKI, M.L., Chudoba, K.M., (2000). Bridging space over time: Global virtual team dynamics and effectiveness, Organization Science, II(5), 473-492. doi: 10.1287/ orsc. II.5.473.15200

MERRIAM, S.B. (20I4). Qualitative research: A guide to design and implementation. John Wiley \& Sons.

MINAS, R.K., Potter, R.F., Dennis, A.R., Bartelt, V., Bae, S. (20/4). Putting on the thinking cap: Using neurolS to understand information processing biases in virtual teams. Journal of Management Information Systems, 30(4), 49-82. doi: I0.2753/MIS0742-I 222300403

MUNKVOLD, B., Zigurs, I. (2007). Process and technology challenges in swift-starting virtual teams. Information \& Management, 44(3), 287-299. doi:10.1016/j.im.2007.01.002

PAUL, S., Seetharaman, P., Samarah, I., Mykytyn, P.P., (2004). Impact of heterogeneity and collaborative conflict management style on the performance of synchronous global virtual teams. Information \& Management, 4 I (3), 30332I. doi:I0.1016/S0378-7206(03)00076-4

POLTROCK, S.E., and Engelbeck, G. (1999). Requirements for a virtual collocation environment. Information and Software Technology, 4I(6), 33I-339. doi:10.1016/509505849(98)00066-4

PURVANOVA, R.K. and Bono, J.E. (2009). Transformational leadership in context: Face-to-face and virtual teams. The Leadership Quarterly, 20(3), 343-357. doi:10.1016/j. leaqua.2009.03.004 
REZGUI, Y. (2007). Exploring virtual team-working effectiveness in the construction sector. Interacting with Computers, 19(I), 96-II2. doi: doi:10.1016/j. intcom.2006.07.002

RIOPELLE, K., Gluesing, J.C., Alcordo, T.C., Baba, M.L., Britt, D., McKether, W., Monplaisir, L., Ratner, H.H., Wagner, K.H. (2003). Context, task, and the evolution of technology use in global virtual teams. In: Gibson, C.B., Cohen, S.G. (Eds.), Virtual Teams that Work: Creating Conditions for Virtual Team Effectiveness. Jossey-Bass, San Francisco.

ROSEN, B., Furst, S.A., Blackburn, R.S. (2007). Overcoming barriers to knowledge sharing in virtual teams, Organizational Dynamics, 36(3), 259-273. doi:10.1016/j.orgdyn.2007.04.007

ROWLEY, J. (2002). Using case studies in research. Management research news, 25(I), 16-27. doi: 10.1108/01409170210782990

RUSMAN, E., van Bruggen, J. Sloep, P., Koper, R. (20I0). Fostering trust in virtual project teams: Towards a design framework grounded in a TrustWorthiness ANtecedents (TWAN) schema. International Journal of Human-Computer Studies, 68(II), 834-850. doi:10.1016/j.ijhcs.2010.07.003

SCHILLER, S., Mennecke, B.E., Nah, F.F.H., Luse, A. (20I4). Institutional boundaries and trust of virtual teams in collaborative design: An experimental study in a virtual world environment. Computers in Human Behavior, 35, 565577. doi:10.1016/j.chb.2014.02.05 I

SHACHAF, P. (2008). Cultural diversity and information and communication technology impacts on global virtual teams: An exploratory study, Information \& Management, 45(2), |3|-|42. doi:10.10|6/j.im.2007.12.003

SHEN, Z., Lyytinen, K., Yoo, Y. (20/4). Time and information technology in teams: a review of empirical research and future research directions. Forthcoming in European Journal of Information Systems. doi: 10.1057/ejis.2014.8

VALACICH, J.S., Dennis, A.R., Connolly, T. (1994). Idea generation in computer-based groups: A new ending to an old story. Organizational Behavior and Human Decision Processes, 57(3), 448-467. doi: I 0. I006/obhd. I994. 1024

WEIHRICH, H. (1982). The TOWS Matrix - A Tool for Situational Analysis. Long Range Planning, 15(2), 54-66. doi:I0.10I6/0024-630I(82)90I20-0

YIN, R.K. (20I4). Case study research: Design and methods. Sage publications.
ZACCARO, S., Bader, P. (2003). E-leadership and the challenges of leading e-teams: Minimizing the bad and maximizing the good, Organizational Dynamics, 3I (4), 377387.

ZAKARIA N., Yusof, S.A.M. (20I5). Can we count on you at a distance? The impact of culture on formation of swift trust within global virtual teams. In: Leading Global Teams (pp. 253-268). Springer, New York.

ZIGURS, I. (2003). Leadership in virtual teams: Oxymoron or opportunity? Organizational Dynamics, 3I(4), 339-35I. 